\title{
Neuroscience Research and Mentoring in Puerto Rico: What Succeeds in This Environment?
}

\author{
(D)Gregory J. Quirk \\ Departments of Psychiatry and Anatomy \& Neurobiology, University of Puerto Rico School of Medicine, San Juan, Puerto Rico 00936
}

Twenty years ago, I arrived in Puerto Rico from New York City to establish a neuroscience laboratory and research program on extinction of conditioned fear. The lab's first research paper appeared in the Journal of Neuroscience (Quirk et al., 2000) and has been cited $>900$ times. The success of this project in Puerto Rico far surpassed my original expectations. Therefore, I thought it might be useful to identify the factors responsible for this success, with the hope of facilitating the development of laboratories in diverse settings. A description of our lab practices is interspersed with personal statements from trainees hailing from Puerto Rico and other parts of Latin America. Creating an effective research and training environment depends less on the director's personality and more on the proper practice of activities that foster intellectual growth, such as journal clubs, lab meetings, and philosophy of science retreats. On a personal level, this project has been enormously gratifying. The unique environment in Puerto Rico fostered my best work, and I am very happy to have established my laboratory here.

\section{Introduction}

The first Journal of Neuroscience paper from Puerto Rico focused on extinction of conditioned fear. In August of 1997, I arrived in Ponce, Puerto Rico as an Assistant Professor at Ponce School of Medicine (now Ponce Health Sciences University) as the school's only neuroscientist. After completing postdoctoral training at New York University studying neural mechanisms of fear conditioning with Joseph LeDoux, I was ready to start a laboratory on fear extinction by building on the clinical usefulness of fear reduction in individuals with anxiety disorders. At that time, there were few studies on neural mechanisms of extinction, with most work focusing on acquisition of conditioned fear. LeDoux's group had shown that lesions of ventral medial prefrontal cortex in rats (vmPFC) delayed extinction across days (Morgan et al., 1993, 2003), suggesting that prefrontal lesions induced emotional perseveration (Sotres-Bayon et al., 2004). However, Mike Davis' group found no effect of such lesions on extinction (Gewirtz et al., 1997).

Together with a small band of trainees (two medical students and one graduate student), we attempted to resolve this apparent conflict by: (1) using a fear conditioning protocol in which tones

Received Sept. 14, 2018; revised 0ct. 28, 2018; accepted 0ct. 30, 2018.

This work was supported by National Institutes of Health Grants R37-MH058883 and P50-MH106435; National Science Foundation Grant 15-PAF06754; the University of Puerto Rico; and the Puerto Rico Science, Technology, and Research Trust. This project would not have been possible without advice, grants, and awards from the National Institute of Mental Health, in particular program officers Kevin Quinn, Kathleen Andersen, and Aleksandra Vicentic. I acknowledge my own mentors for their superb training, words of encouragement, and frequent visits to Puerto Rico: Aryeh Routtenberg (1940-2016, my undergraduate mentor at Northwestern University), Robert Muller (1942-2013, my graduate mentor at State University of New York-Downstate), and Joseph LeDoux (my postdoctoral mentor at New York University). I thank my husband, Ricardo Magbitang, for sacrifices in accompanying me to Puerto Rico and sage advice throughout this project. A blog discussion of this article can be found at https:// quirklab653019525.wordpress.com/.

The authors declare no competing financial interests.

Correspondence should be addressed to Gregory J. Quirk at gregoryjquirk@gmail.com.

https://doi.org/10.1523/JNEUROSCI.2352-18.2018

Copyright $\odot 2019$ the authors $\quad 0270-6474 / 19 / 390776-07 \$ 15.00 / 0$ and shocks are delivered while rats are pressing for food (Annau and Kamin, 1961), thereby decreasing freezing between tones and eliminating ceiling effects; (2) distinguishing within-session declines in freezing from subsequent recall of extinction memory; and (3) dissociating the effects of lesions of rostral versus caudal vmPFC. We observed that rats with lesions of the caudal vmPFC showed normal extinction within a session but were severely impaired in their recall of extinction the following day (Quirk et al., 2000). Thus, vmPFC was not necessary for trial-to-trial reductions in freezing but was necessary for consolidation of extinction memory.

This paper emphasized extinction as a separate form of learning: with acquisition, consolidation, and recall phases. We went on to show that neurons in the infralimbic (IL) subregion of vmPFC signaled recall of extinction and stimulation of IL that mimicked this activity could induce recall of extinction (Milad and Quirk, 2002). Successful recall of extinction required posttraining NMDA receptor activity (Santini et al., 2004) and bursttype firing (Burgos-Robles et al., 2007) in IL, and infusing BDNF into IL could induce extinction recall, even in the absence of training (Peters et al., 2010). These initial studies spurred subsequent work on the neural mechanisms of fear extinction in rodents, implicating prefrontal-amygdala circuits (for review, see Milad and Quirk, 2012; Bukalo et al., 2014; Duvarci and Pare, 2014; Arruda-Carvalho and Clem, 2015; Giustino and Maren, 2015; Tovote et al., 2015).

\section{Other accomplishments of the "Fear Lab" in Puerto Rico}

The laboratory in Ponce was not my first experience in Latin America. Before arriving in Puerto Rico, I established a small neuroscience laboratory in Honduras, with a 1 year Fulbright Grant to study the developmental effects of malnutrition on the brain (Quirk, 1995; Quirk et al., 1995; Hesse et al., 1998). This positive experience galvanized my interest in doing neuroscience in places where it would have a greater impact (Quirk and Casco, 
1994; Quirk, 2017); and for this reason, I returned to Latin America following my postdoc at New York University. Upon arriving in Ponce, I realized the challenges to establishing a productive research laboratory: very few neuroscience colleagues, students with scant research experience, and limited institutional support in terms of startup funds or teaching relief. This would require creative approaches and workarounds. After 10 years in Ponce, I was recruited by the University of Puerto Rico School of Medicine in San Juan. This move allowed me to expand the lab and extend my rodent research to monkeys and humans. I was initially supported by a National Institutes of Health diversity program: the Minority Biomedical Research Support of National Institute of General Medical Sciences, and later by a FIRST Award (R29) from National Institute of Mental Health. Renewed four times, this National Institute of Mental Health Grant was the first Grant from Puerto Rico to receive a Presidential Early Career Award and later a National Institutes of Health MERIT Award. Other grant "firsts" for Puerto Rico were a CONTE Center P50 subaward, a Pathway to Independence Award (K99-R00) for my postdoc, and Dissertation Completion Awards (R36) for my graduate students, all funded by National Institute of Mental Health.

Interest in fear extinction has rapidly increased. Rodent-based circuits have been translated to humans, advancing our understanding of the etiology and treatment of post-traumatic stress disorder and obsessive compulsive disorder (Milad and Quirk, 2012; Milad and Rauch, 2012; Pitman et al., 2012; Dunsmoor et al., 2015; Marin et al., 2017; Fullana et al., 2018). Perhaps the timely selection of fear extinction as the focus of the lab contributed to its success. More recently, my laboratory has explored circuits of active avoidance, obsessive-compulsive disorder, and frustration using deep-brain stimulation, optogenetics, and CRISPR-Cas9 techniques (Do-Monte et al., 2015, 2017; Rodriguez-Romaguera et al., 2016; Diehl et al., 2018; Rosas-Vidal et al., 2018).

Our work in Puerto Rico has produced $\sim 80$ papers, which are cited $\sim 2000$ times a year (Google Scholar). Some of these papers were the first from Puerto Rico to appear in their respective journals (Science, Neuron, Journal of Neuroscience, Biological Psychiatry, Neuropsychopharmacology, Molecular Psychiatry, Annual Review of Psychology). Perhaps the most significant accomplishment is the training of 130 young people in the laboratory, $90 \%$ of whom are from Puerto Rico and Latin America and $50 \%$ of whom are women. This number includes faculty, residents, and postdoctoral fellows, $\mathrm{PhD}$ and PsyD students, MD students, undergraduates, and technicians. Many of these trainees have gone on to successful postdoctoral fellowships, clinical practice, and faculty positions in Latin America and the U.S., strengthening the image of Puerto Rico in neuroscience.

\section{What made this lab successful?}

The success of a research laboratory is due to many factors. While the prior experience of the Principal Investigator (PI) is important, I believe a lab's success depends more on the practice of specific activities that create the optimal environment. Indeed, there are four activities (most of which are practiced to some extent in most laboratories) that were key in the development of this lab: weekly Journal Clubs, weekly lab meetings, weekly individual meetings, and yearly Philosophy of Science Retreats. Done regularly, these four activities develop skills of logic, communication, and intellectual inquisitiveness in trainees while also building group cohesiveness. While some PIs may balk at the time investment ( 3 meetings per week, $\sim 22 \mathrm{~h}$ per month), these activities can bring trainees from very low analytic levels to virtually any higher level, depending on the duration of training. The investment of time pays off from both the mentoring and research perspectives. Especially for laboratories located "off the beaten track," this practice can diversify science and bring fresh perspectives to scientific problems.

The key to the effectiveness of lab activities is their proper execution within a given context. Regular lab meetings and Journal Clubs can have a large impact in environments with limited resources. Below is a detailed description of how we perform these activities in Puerto Rico. Descriptions are interspersed with quotes from former trainees who attended a retreat celebrating the 20th anniversary of the lab (for photos, see https://md.rcm. upr.edu/quirk/wp-content/uploads/sites/52/2018/02/collage-QLAB20.png).

\section{The Journal Club as a teaching tool}

Perhaps more than any other activity, weekly Journal Clubs help trainees develop scientific thinking and expertise in the field. In many labs, Journal Clubs are often sporadic due to travel schedules or work conflicts. For this reason, our Journal Clubs are always scheduled at the same day and time (Fridays 4:00 P.M. to 5:30 P.M. in recent years). Once the day/time is decided by the group, it is never changed, thus avoiding the scheduling uncertainty than can kill a Journal Club. Attendance is mandatory for all trainees as well as myself. Excuses, such as "I'm running an important experiment" or "I'm too busy," are not acceptable. Someone being out of town does not justify cancellation of the Journal Club (this includes the PI). Journal Clubs are for my lab only (12 people), rather than a larger multilab group. The smaller size facilitates discussion and free exchange of ideas. At its peak, my lab consisted of $\sim 13$ trainees at any given time (4 graduate students, 3 postdocs, 6 undergrads or postbacs).

"Understanding that the Journal Club was a priority taught me the lesson of the seriousness of our commitments and priorities in life."

$$
\text { —David Anglada }
$$

"I realize we are critiquing others' work in the same way they will be critiquing my work."

\section{—Demetrio Sierra-Mercado}

"I could've felt like a mere spectator, but I was always encouraged to think and participate actively, even by just asking a question."

$$
\text { —Angelica Minier-Toribio }
$$

"It taught me how to get the most important point out of an article, a skill I have passed on to my own students." —Annelyn Torres-Reveron

Trainees who signed up in advance to act as a Journal Club mediator are tasked with selecting a recent article (with my approval) and distributing it to the group at the start of the week. Everyone is expected to carefully read the article. The mediator writes a short one-page summary in advance, which is critiqued by the group during the first $20 \mathrm{~min}$ of the meeting. The summary states the scientific question and approach (paragraph 1), the overall findings (paragraph 2), its relevance to our lab, and a suggested experiment based on the article's findings (paragraph 3 ). This exercise provides trainees with 
continued practice in effective writing. Everyone then states their general impressions of the article and its suitability for the journal in which it appeared. The mediator then leads the discussion by going through each of the article's figures in an orderly fashion, making sure that everyone understands the science. It's notable how often people thought they understood a figure only to discover they missed something important. This also keeps everyone on track about the study's logic and strategy.

"The JClub write-up was an opportunity for me to expose my writing and thinking and receive critiques to improve." -Jose Rodriguez-Romaguera

"Designing an experiment in the third paragraph opened-up my creativity and expanded my toolset."

—Kelvin Quiñones-Laracuente

"It was like a stress inoculation tool that prepared me for future critiques of my papers and grants."

$$
\text { -Mohammed R. Milad }
$$

"Writeups were a challenge: to write from scratch with my own brain."

$$
\text { —Estefanía Gonzáles-Araya }
$$

Throughout the discussion, I interject challenging comments and search for "teachable moments." For example, if the mediator has said something that I thought few understood, I will ask whether everyone understood what she said, or whether anyone can explain it. If the finding is controversial or challenging, I will ask whether people are comfortable with the unexpected conclusion. Sometimes trainees go to the whiteboard to explain the concept. This gets everyone actively involved and committed to an opinion about the work. Conversation can get heated at times or long-winded, so it is up to the PI is to keep the discussion on track, curtailing repetitious comments and preventing a few individuals from dominating the discussion. It is always impressive to watch the group fervently discussing a highly technical paper, especially on a Friday evening.

"When I didn't understand something, I didn't feel ashamed for not knowing."

$$
\text { -Patricia Hernandez }
$$

"These weekly discussions helped me gain confidence and a sense of belonging, which lasted way longer than 90 mins!"

$$
\text { —Angelica Minier-Toribio }
$$

"Journal Clubs were scary but I needed to be able to defend my understanding of the paper: there was no other option."

$$
\text { —Fabiola Gonzalez-Diaz }
$$

"After years of JClubs, you are never again satisfied with mediocre efforts."

—David Anglada

\section{Lab meetings: 12 brains are better than one}

Similar to Journal Clubs, weekly lab meetings are $90 \mathrm{~min}$ and take place on a fixed day/time. Trainees organize their experiments around these meetings. In recent years, we start with 5 min of "mindfulness" or guided meditation from the internet

\section{Table 1. Websites used in lab meetings}

\author{
5 min guided meditations \\ https://www.youtube.com/watch?v=i50ZAs7v9es \\ https://www.youtube.com/watch?v= Q2UKw8tFYyY \\ https://www.youtube.com/watch?v=LDu4-dyA7DE \\ National Institutes of Health Neuroscience Seminar Series \\ https://videocast.nih.gov/PastEvents.asp?c $=16$ \\ TED Neuroscience Talks
}

https://www.ted.com/topics/neuroscience

(for websites, see Table 1), following a similar practice at Google headquarters (https://www.youtube.com/watch?v= 3 nwwKbM_vJc). This practice helps calm the group and be more present at the meeting. This is followed by "appreciations," an opportunity for people to acknowledge someone who may have helped them that week (e.g., "Jose for bringing my rats back to the animal facilities," "Maria for comments on my fellowship application"). In addition to making the helper feel good, appreciations inform everyone about what's happening in the lab and foster a culture of cooperation. Appreciations are followed by concerns: problems that came up during the week that affect the lab or need to be discussed/ resolved by the group (Institutional Animal Care and Use Committee problems, lab cleanliness, etc). This is followed by presentations by trainees. Trainees sign up in advance to present their data at lab meetings (one project per meeting). The presenter gives a PowerPoint presentation of their project, and everyone chimes in with questions, comments, and suggestions. These presentations ensure that everyone knows what each person is doing/thinking in the lab and can help guide it. With each slide, presenters state the scientific question they are investigating before showing the data that address that question. Presenters sometimes ask the group to make predictions before showing the results, to increase the group's involvement.

"As a newcomer, I felt lab meetings were a speedway with people talking so fast, but slowly I began picking up speed and joined the conversations."

—Kelvin Quiñones-Laracuente

"I hated lab meetings at first because it was terrifying to be challenged in front of others; but I later learned how to be better prepared for what I would be questioned about."

—Mohammed R. Milad

If no one has data ready to discuss for a given week, we listen to a neuroscience seminar from National Institutes of Health, TED, or other online sources (for websites, see Table 1). Videos of seminars are especially important in institutions with few visiting scientists. In addition to receiving cutting-edge ideas, the students become familiarized with colleagues in the field so that they can more easily approach them at conferences. An advantage of video seminars over live seminars is that talks can be paused to clarify something, or to stimulate people's thinking ("Where do you think she is heading with this?" "Do you agree with his statement?"). Like online access to papers, video seminars minimize the disadvantages of being at a smaller institution. Occasionally, lab meetings are used to review the lab's publication progress. Trainees indicate the 
manuscripts they are working on, along with their expected date of submission. The list is revisited every 2 months and updated as necessary. While this may be uncomfortable for some, most find it helpful to review their progress (projects always take longer than originally planned).

"I would sign up for a lab meeting before I had all my data analyzed, but I knew I had to have everything done by that date."

$$
\text { -Hector Bravo-Rivera }
$$

"Those meetings gave me a big picture of how a lab is run." -Estefanía Gonzáles-Araya

"It was impressive when I found a Quirk Lab member presenting another member's poster without being part of the study: lab meetings turned every member into defenders of the others' projects."

-Christian Bravo-Rivera

\section{Effective communication between lab members}

Our lab puts great emphasis on effective communication. Sloppy communication leads to failed experiments, which delay the development of trainees. This is especially true of young people who may have formed the habit of halfcommunicating an idea that in turn is only half-understood by the listener. In Puerto Rico, the inclination to be socially polite rather than request clarification aggravates this problem. To address this, we focus on trying to fully understand each other in the lab, while freely admitting when we do not. Asking the explainer to repeat an explanation or asking others to try to explain the concept helps. The explainer may realize that they do not fully grasp the concept ("I crashed"). By the time the issue is resolved, trainees will have a fuller understanding of the concept. More importantly, they have a better sense of what complete understanding "feels" like, raising the standard for themselves and for those with whom they communicate.

"The lab was truly a communication learning lab." —David Anglada

"I liked it when Greg said, 'I crashed' because it validated my crashing and grounded Greg."

$$
\text { -Alexis Vega-Medina }
$$

"I've learned to talk again."

$$
\text { —Kelvin Quiñones-Laracuente }
$$

The situation is more pressing for written communication, especially if English is not someone's first language. Critiquing the summaries in Journal Club is a start, but the real test is the writing of abstracts and papers. The challenge of effective writing is to imagine what the reader is thinking, and then create the idea you want in the reader's mind. In effect, it is writing for a brain that is not yours, always evaluating your writing from the reader's point of view. It is therefore difficult to objectively critique one's own writing. After multiple versions with the trainee, manuscripts in my lab follow the "6-Eyes Rule": asking three outside readers to edit and critique the manuscript (in track changes) before submission. Passages that failed with two of the three readers must be reworked, no matter how "perfect" they may seem to the author.

"I had to rewrite the Intro of my first paper 30 times, but I'm so glad I went through that painful process to develop my English and writing skills."

$$
\text { —Anthony Burgos-Robles }
$$

"I remember Greg's analogy of pretending to play a violin while you were being too flowery and not going straight to the point."

$$
\text { —Mohammed R. Milad }
$$

"The 6-Eyes Rule became part of everything I do after the Quirk lab."

—Mohammed R. Milad

\section{Individual meetings: FaceTime}

Another useful practice are one-on-one individual meetings I have with each trainee (grad student, postdoc, technician, the occasional undergrad), on a weekly or biweekly basis. While this adds more meetings to the week, it provides a needed deadline for trainees to collect their ideas, analyze their data, prepare a first draft, etc. The idea of individual meetings in my lab originated from my students in a prior retreat, and it has worked for us. It allows me to give input before a project goes too far in the wrong direction. Ideally, trainees post their data on our Google Drive folder 1-2 $\mathrm{d}$ in advance, so that I have a chance to look at it before the meeting. Most trainees are prepared for their meetings but occasionally there's a student who is "all talk and no data." This is a clear sign of a problem that needs to be addressed.

We call that "tap dancing." - Hector Bravo-Rivera

The more personal setting of the individual meeting also allows trainees to reveal any anxieties they might have about their progress or career goals. Often all that's needed is a fresh perspective from the mentor's point of view, which helps the trainee reset or reframe.

"We were constantly challenged during individual meetings to understand the "why" and the "how" of the data." -Annelyn Torres-Reveron

"This is where the rubber hit the road." —David Anglada

"This was a firm deadline to make my data presentable and remind Greg of the importance of my project."

$$
\text { -Maria M. Diehl }
$$

"I would pitch my new ideas and see if they got through or got shot down."

$$
\text { -Hector Bravo-Rivera }
$$

\section{Philosophy retreats in the mountains}

My lab undertakes a 3 d Philosophy of Science Retreat every winter. Soon after arriving in Puerto Rico, I realized that the next generation of neuroscientists here would need a foundation about knowledge itself: What is science and what does it mean to be a scientist? Some of what trainees learned in their primary education about the acquisition of knowledge and the pursuit of truth would have to be challenged. They would also need to acquire the cognitive tools to choose appropriate research ques- 


\section{Table 2. Materials used on Philosophy of Science Retreats}

\begin{tabular}{l}
\hline Books \\
The logic of scientific discovery (Karl R. Popper, London: Routledge, 2000) \\
The structure of scientific revolutions, Ed 4 (Thomas S. Kuhn, Chicago: University of \\
Chicago, 2012) \\
Advice for a young investigator (Santiago Ramón y Cajal, Cambridge, MA: Massachusetts \\
Institute of Technology Press, 1999) \\
The 7 habits of highly effective people (Stephen R. Covey, New York: Simon \& Schuster, \\
2013) \\
Pasteur's quadrant: basic science and technological innovation (Donald E. Stokes, \\
Washington, DC: Brookings Institution Press, 1997) \\
Ignorance: how it drives science (Stuart Firestein, Oxford: Oxford UP, 2012) \\
Personality Tests \\
The NEO PI: http://www.personalitytest.org.uk/ \\
Keirsey Temperament Sorter: http://www.keirsey.com/sorter/register.aspx \\
Enneagram Test: https://enneagramtest.net/
\end{tabular}

tions, overcome their inherent bias (or at least understand it), and handle unexpected outcomes. Rather than discuss data, the idea of the retreats is to examine the philosophical issues that define us as scientists and underlie our approach to scientific questions.

"I needed these retreats to understand what it is to be a scientist because I really didn't know."

$$
\text { -Mohammed R. Milad }
$$

"Retreats were more about who you are than what you do." -Fabiola Gonzalez-Diaz

"The retreat gave me the security to rely on the other people in the lab."

$$
\text { —Jorge Iravedra-García }
$$

For retreat readings, we cycle through six books (one per year), repeating the cycle with each new group of trainees (for a list of readings, see Table 2). The books cover a wide range of topics from Kuhn's Scientific revolutions to Covey's Seven habits of highly effective people. Retreats run from Friday afternoon to Sunday afternoon and are usually held at a traditional parador (bed and breakfast accommodation) in the mountains (mountains are better than the beach for discussing philosophy). We use funds from the institution to cover lodging and meals. All trainees in the lab are required to attend (for a list of trainees quoted in this article, see Table 3). Over $2 \mathrm{~d}$, we hold four $2 \mathrm{~h}$ meetings, plus an afternoon athletic activity. While three of the meetings are used to cover the book, one meeting is always reserved for group dynamics and team building. This can involve resolving personality conflicts or learning what makes each other tick with the help of simple personality tests (for online tests, see Table 2). These tests are remarkably good at revealing our characteristics and tendencies, helping us to work together in close quarters. Some years, in lieu of a book, sessions focus on other issues relevant to science practice, such as women in science, making the next career move, God and science, writing a lab mission statement, etc. (Barker, 2010). Retreats build a sense of purpose and mission. Sharing meals together, playing soccer, and late-night poker games really bond us. A relaxed "post-retreat" environment is felt for weeks. Even years later, my graduate student is quoting Popper about the next falsifying experiment he is planning...

\section{Table 3. Quoted trainees and their work}

Anthony Burgos-Robles

Angelica Minier-Toribio

Annelyn Torres-Reveron

Alexis Vega-Medina

Christian Bravo-Rivera

David Anglada

Demetrio Sierra-Mercado

Estefanía Gonzáles-Araya

Fabiola Gonzalez-Diaz

Gabriela Manzano Nieves

Hector Bravo-Rivera

Jorge Iravedra-García

Jose Rodriguez-Romaguera

\section{Kelvin Quiñones-Laracuen}

Maria M. Dieh

Mohammed R. Milad

Patricia A. Rubio

Patricia Hernandez (former Undergraduate and PhD student) Identified extinctioninduced NMDA-dependent burst firing in IL neurons, and characterized PL activity in fear conditioning. He is now a post-doctoral fellow at MIT.

(former Undergraduate) Identified a role of PVT-accumbens projections in reward-omission (frustration). She completed her postbaccalaureate training at NIDA and is now a graduate student at Mt. Sinai School of Medicine.

(former PhD student) Worked on extinction of cocaine addiction in the early days of the lab. She is now an Assistant Professor at University of Texas-Rio Grande Valley.

(former Post-baccalaureate) Worked on BDNF signaling in extinction of avoidance. He is now a post-baccalaureate trainee at Univ. of Michigan.

(former Undergraduate and PhD student) Developed the platformmediated active avoidance task and characterized prefrontalstriatal-amygdala involvement in avoidance. He is now a postdoctoral fellow at Cold Spring Harbor Laboratories.

(former PsyD student) Studied the role of the basolateral amygdala in extinction. After completing a clinical post-doc, he served as Director of Mental Health services for several community health centers in Santa Rosa, $\mathrm{CA}$, and is a pastor of an evangelical Christian church.

(former PhD student) Characterized prefrontal-amygdala-hippocampal roles in fear expression and extinction, using pharmacological and recording techniques. He is now an Assistant Professor at UPR School of Medicine.

(former Undergraduate) Worked on an avoidance-based rat model of OCD symptoms. She is now in a Post-baccalaureate program at NIMH.

(current Undergraduate) She is examining the role of the prelimbic cortex and its projections in active avoidance using optogenetic techniques.

(former Post-doctoral fellow) Worked on circuits of persistent avoidance using anatomical, immunocytochemical (ICC) and optogenetic techniques. He is now a post-doctoral fellow at Mt. Sinai School of Medicine.

(former Undergraduate) Used optogenetics to revisit the role of infralimbic cortex in fear extinction. She is in the neuroscience doctoral training program at Brown University.

(current PhD student) Developing new behavioral tasks for the study of approach-avoidance conflict in both monkeys and rats.

(current Undergraduate) Is working on role of different prelimbic circuits in expression of active avoidance.

(former Undergraduate and PhD student) Studied deep brain stimulation (DBS) modulation of fear extinction and developed a rodent model of ERP therapy for OCD. He is now a post-doctoral fellow at University of North Carolina, Chapel Hill.

(current MD/PhD student) Studies time-dependent changes in circuits of fear retrieval with unit recording and optogenetic techniques.

(current Post-doctoral fellow) Identified a prelimbic signal of avoidability and is characterizing the role of prelimbic projections in expression of active avoidance.

(former PhD student) Identified infralimbic signaling of fear extinction in rats. As a post-doctoral fellow and faculty member of Harvard-MGH he transferred rodent extinction models to human anxiety disorders. He is now a Professor at University of lllinois at Chicago.

(former Post-baccalaureate) Was the first in the lab to study female rats, characterizing their response to approach-avoidance conflict. She is now a doctoral student in the neuroscience program of Northeastern University.

(former PsyD student) Worked on anatomical differences in infralimbic cortex correlated with extinction. She was then a clinical post-doctoral fellow in lowa and has served an inpatient Psychologist in Puerto Rico. 
"The 'Seven Habits' helped me embrace win-win situations."

$$
\text { —Jose Rodriguez-Romaguera }
$$

"I felt empowered by Cajal and I could relate to him; he was like an uncle."

$$
\text { —Kelvin Quiñones-Laracuente }
$$

"Cajal challenged my excuses for not succeeding." - Hector Bravo-Rivera

"Now I understand why Maria enforces the rules and why it's important."

$$
\text { -Patricia A. Rubio }
$$

"The retreat not only challenged my views on science, but also my purpose as a scientist."

$$
\text { —Angelica Minier-Toribio }
$$

"Lab retreats gave me a sense of belonging."

$$
\text { —Estefanía Gonzáles-Araya }
$$

\section{Work teams: passing on the mentoring style}

Another challenge for the university laboratory is the hosting of undergraduate students. More schools are offering Neuroscience majors that require students to complete a thesis project. Undergraduates are limited in their commitment to a research question, at least at the start. Many PIs feel that training undergraduates is a poor use of time and resources. Indeed, I started my lab with this view, but eventually realized that undergraduates can become a key resource, with the right training. After passing a group interview with the entire lab, our undergraduates are assigned to a specific graduate student or postdoc who will mentor them and direct their contribution to his/her project. Each graduate or postdoc mentor directs 2-4 undergraduate mentees, forming a work team. In this way, the mentoring style that benefitted the graduate student is passed on to her mentees, thereby developing leadership and mentoring skills in the graduate student. Undergraduate students participate in the lab meetings and retreats and are expected to present papers in Journal Clubs. As often as possible, we take the time to explain difficult concepts and keep undergraduates "on board" during meetings. Each mentor spends time with his mentees outside of lab meetings, helping them grasp key ideas and building their critical thinking. This intensive training prepares undergraduates for summer research outside of Puerto Rico, and eventually for graduate school.

"As a postdoc-mentor, I enjoyed working with my undergraduate on understanding the JClub paper."

$$
\text { -Freddyson Martinez-Rivera }
$$

"It was the mentor's job to make sure the undergraduate was productive and getting the necessary training."

- Gabriela Manzano Nieves

"When I failed, my mentor failed. When he didn't have time to write because of all the experiments, I felt I had to step up my game- we were a team."

- Gabriela Manzano Nieves

\section{Conclusion}

I have discussed the important factors for the successful operation of my research laboratory in Puerto Rico, following our first paper in the Journal of Neuroscience almost 20 years ago. For additional ideas about running a lab, I strongly recommend Kathy Barker's book At the helm (Barker, 2010), and a recent Special Issue of Nature devoted to growing a healthy lab (May 17, 2018). One overriding theme of our lab is a family-like atmosphere, mirroring the importance of family values in Latin culture. Trainees are more likely to spend time away from their families if the lab feels like a family. Furthermore, those graduating from the lab continue to help each other long after leaving the lab, perhaps because they share a common bond. Of course, we've had our difficulties over the years, such as personality conflicts, unexpected deaths, and category 4 hurricanes. However, building a bond of trust, together with regular meetings and retreats, provides the tools needed to resolve whatever problems come our way. As a PI, it is important to remember that you can create whatever lab environment you want, setting the tone that trainees will follow. The challenge is to visualize that environment and determine how it might fit (or not fit) with the local culture; it is not "one size fits all." With a good match and sufficient investment of time, you can create a happy and productive laboratory in any environment.

\section{References}

Annau Z, Kamin LJ (1961) The conditioned emotional response as a function of intensity of the US. J Comp Physiol Psychol 54:428-432. CrossRef Medline

Arruda-Carvalho M, Clem RL (2015) Prefrontal-amygdala fear networks come into focus. Front Syst Neurosci 9:145. CrossRef Medline

Barker K (2010) At the helm: leading your laboratory, Ed 2. Cold Spring Harbor, NY: Cold Spring Harbor Laboratory.

Bukalo O, Pinard CR, Holmes A (2014) Mechanisms to medicines: elucidating neural and molecular substrates of fear extinction to identify novel treatments for anxiety disorders. Br J Pharmacol 171:4690-4718. CrossRef Medline

Burgos-Robles A, Vidal-Gonzalez I, Santini E, Quirk GJ (2007) Consolidation of fear extinction requires NMDA receptor-dependent bursting in the ventromedial prefrontal cortex. Neuron 53:871-880. CrossRef Medline

Diehl MM, Bravo-Rivera C, Rodriguez-Romaguera J, Pagan-Rivera PA, Burgos-Robles A, Roman-Ortiz C, Quirk GJ (2018) Active avoidance requires inhibitory signaling in the rodent prelimbic prefrontal cortex. Elife 7:e34657. CrossRef Medline

Do-Monte FH, Quiñones-Laracuente K, Quirk GJ (2015) A temporal shift in the circuits mediating retrieval of fear memory. Nature 519:460-463. CrossRef Medline

Do-Monte FH, Minier-Toribio A, Quiñones-Laracuente K, Medina-Colon EM, Quirk GJ (2017) Thalamic regulation of sucrose seeking during unexpected reward omission. Neuron 94:388-400.e4. CrossRef Medline

Dunsmoor JE, Niv Y, Daw N, Phelps EA (2015) Rethinking extinction. Neuron 88:47-63. CrossRef Medline

Duvarci S, Pare D (2014) Amygdala microcircuits controlling learned fear. Neuron 82:966-980. CrossRef Medline

Fullana MA, Albajes-Eizagirre A, Soriano-Mas C, Vervliet B, Cardoner N, Benet O, Radua J, Harrison BJ (2018) Fear extinction in the human brain: a meta-analysis of fMRI studies in healthy participants. Neurosci Biobehav Rev 88:16-25. CrossRef Medline

Gewirtz JC, Falls WA, Davis M (1997) Normal conditioned inhibition and extinction of freezing and fear-potentiated startle following electrolytic lesions of medial prefrontal cortex in rats. Behav Neurosci 111:712-726. CrossRef Medline

Giustino TF, Maren S (2015) The role of the medial prefrontal cortex in the conditioning and extinction of fear. Front Behav Neurosci 9:298. CrossRef Medline

Hesse H, Rivera MF, de Díaz I, Quirk GJ (1998) Central somatosensory conduction time in severely growth-stunted children. Am J Clin Nutr 67:93-96. CrossRef Medline

Marin MF, Zsido RG, Song H, Lasko NB, Killgore WD, Rauch SL, Simon NM, Milad MR (2017) Skin conductance responses and neural activations during fear conditioning and extinction recall across anxiety disorders. JAMA Psychiatry 74:622-631. CrossRef Medline

Milad MR, Quirk GJ (2002) Neurons in medial prefrontal cortex signal memory for fear extinction. Nature 420:70-74. CrossRef Medline 
Milad MR, Quirk GJ (2012) Fear extinction as a model for translational neuroscience: ten years of progress. Annu Rev Psychol 63:129-151. CrossRef Medline

Milad MR, Rauch SL (2012) Obsessive-compulsive disorder: beyond segregated cortico-striatal pathways. Trends Cogn Sci 16:43-51. CrossRef Medline

Morgan MA, Romanski LM, LeDoux JE (1993) Extinction of emotional learning: contribution of medial prefrontal cortex. Neurosci Lett 163: 109-113. CrossRef Medline

Morgan MA, Schulkin J, LeDoux JE (2003) Ventral medial prefrontal cortex and emotional perseveration: the memory for prior extinction training. Behav Brain Res 146:121-130. CrossRef Medline

Peters J, Dieppa-Perea LM, Melendez LM, Quirk GJ (2010) Induction of fear extinction with hippocampal-infralimbic BDNF. Science 328:12881290. CrossRef Medline

Pitman RK, Rasmusson AM, Koenen KC, Shin LM, Orr SP, Gilbertson MW, Milad MR, Liberzon I (2012) Biological studies of post-traumatic stress disorder. Nat Rev Neurosci 13:769-787. CrossRef Medline

Quirk GJ (1995) Starting a neuroscience research laboratory in a developing country: a Fulbright experience in Honduras. Am J Physiol 269:S61-S67. CrossRef Medline

Quirk GJ (2017) Less fear, more diversity. PLoS Biol 15:e2002079. CrossRef Medline

Quirk GJ, Casco L (1994) Stress disorders of families of the disappeared: a controlled study in Honduras. Soc Sci Med 39:1675-1679. CrossRef Medline

Quirk GJ, Mejia WR, Hesse H, Su H (1995) Early malnutrition followed by nutritional restoration lowers the conduction velocity and excitability of the corticospinal tract. Brain Res 670:277-282. CrossRef Medline

Quirk GJ, Russo GK, Barron JL, Lebron K (2000) The role of ventromedial prefrontal cortex in the recovery of extinguished fear. J Neurosci 20:62256231. CrossRef Medline

Rodriguez-Romaguera J, Greenberg BD, Rasmussen SA, Quirk GJ (2016) An avoidance-based rodent model of exposure with response prevention therapy for obsessive-compulsive disorder. Biol Psychiatry 80:534-540. CrossRef Medline

Rosas-Vidal LE, Lozada-Miranda V, Cantres-Rosario Y, Vega-Medina A, Melendez L, Quirk GJ (2018) Alteration of BDNF in the medial prefrontal cortex and the ventral hippocampus impairs extinction of avoidance. Neuropsychopharmacology 43:2636-2644. CrossRef Medline

Santini E, Ge H, Ren K, Peña DO, Quirk GJ (2004) Consolidation of fear extinction requires protein synthesis in the medial prefrontal cortex. J Neurosci 24:5704-5710. CrossRef Medline

Sotres-Bayon F, Bush DE, LeDoux JE (2004) Emotional perseveration: an update on prefrontal-amygdala interactions in fear extinction. Learn Mem 11:525-535. CrossRef Medline

Tovote P, Fadok JP, Lüthi A (2015) Neuronal circuits for fear and anxiety. Nat Rev Neurosci 16:317-331. CrossRef Medline 